\title{
Asthma control in Canada remains suboptimal: The Reality of Asthma Control (TRAC) study
}

\author{
J Mark FitzGerald MD FRCPC ${ }^{1}$, Louis-Philippe Boulet MD FRCPC ${ }^{2}$, R Andrew Mclvor MD FRCPC ${ }^{3}$, \\ Sabrina Zimmerman $\mathrm{BSC}^{4}$, Kenneth R Chapman MD MSc FRCPC ${ }^{5}$
}

\begin{abstract}
JM FitzGerald, L-P Boulet, RA McIvor, S Zimmerman, KR Chapman. Asthma control in Canada remains suboptimal: The Reality of Asthma Control (TRAC) study. Can Respir J 2006;13(5):253-259.
\end{abstract}

BACKGROUND: Two Canadian studies showed that 55\% of patients with asthma had daily symptoms (in 1996) and that $57 \%$ of patients suffered from poorly controlled asthma (in 1999).

OBJECTIVES: To assess the state of asthma control of adult Canadians, and asthma knowledge and practices of Canadian physicians actively involved in the care of patients with asthma.

METHODS: Telephone interviews were conducted with adults 18 to 54 years of age who had been diagnosed with asthma at least six months before the survey, who did not have chronic obstructive pulmonary disease and who had a smoking history of fewer than 20 packyears. Physicians were surveyed by telephone and mail. The surveys took place between April and August 2004.

RESULTS: Almost all (97\%) of the 893 patients believed that they had controlled asthma; however, only $47 \%$ had controlled disease according to symptom-based guideline criteria. Just $39 \%$ of 463 physicians based their treatment recommendations on the Canadian asthma guidelines most or all of the time, despite having a high awareness of them. Only $11 \%$ of patients had written action plans, and one-half of patients with action plans did not use them regularly. Almost three-quarters of patients expressed concerns about taking inhaled corticosteroids.

CONCLUSIONS: Since the last major national survey, guideline implementation has not resulted in significant changes in asthmarelated morbidity. Effective means of knowledge transfer should be developed and implemented to improve the translation of guideline recommendations into care.

Key Words: Adults; Antiasthmatic agents; Asthma; Canada; Health surveys; Self care

$\mathrm{D}_{\mathrm{t}}$ espite the continued development of improved treatments for asthma, and regularly updated, evidence-based Canadian asthma clinical practice guidelines (1-3), asthma control in Canada remains suboptimal (4). Suboptimal asthma control reduces patients' quality of life (5) and increases the risk of asthma exacerbations and mortality $(6,7)$. In addition, poor asthma control burdens the health care system (8-10). In 1996 (11) and 1999 (4), two Canadian studies took important

\section{Le contrôle de l'asthme au Canada demeure sous-optimal : L'étude TRAC sur la réalité du contrôle de l'asthme}

HISTORIQUE : Deux études canadiennes ont révélé que $55 \%$ des patients asthmatiques souffraient de symptômes quotidiens (en 1996) et que 57 \% souffraient d'asthme mal contrôlé (en 1999).

OBJECTIFS : Évaluer l'état du contrôle de l'asthme des adultes canadiens, ainsi que les connaissances sur l'asthme et les pratiques des médecins canadiens qui participent activement aux soins des patients asthmatiques. MÉTHODOLOGIE : Des entrevues téléphoniques ont été menées auprès d'adultes de 18 à 54 ans ayant reçu un diagnostic d'asthme au moins six mois avant l'enquête, ne souffrant pas d'une maladie pulmonaire obstructive chronique et fumant moins de 20 paquets-années. Les médecins ont été sondés par téléphone et par la poste. Les enquêtes ont eu lieu entre avril et août 2004.

RÉSULTATS : Près de la totalité (97 \%) des 893 patients pensaient que leur asthme était contrôlé, mais il l'était dans seulement $47 \%$ des cas d'après les critères fondés sur les symptômes des principes directeurs. Seulement $39 \%$ des 463 médecins fondaient presque toujours ou toujours leurs recommandations de traitement sur les principes directeurs du consensus canadien sur l'asthme, même s'ils connaissaient bien ces principes. Seulement $11 \%$ des patients avaient des plans d'action écrits, et la moitié de ceux qui en avaient un ne l'utilisaient pas régulièrement. Près des trois quarts des patients s'inquiétaient de prendre une corticothérapie en aérosol.

CONCLUSIONS : Depuis la dernière grande enquête nationale, l'implantation des principes directeurs n'a pas entraîné de changements significatifs de la morbidité reliée à l'asthme. Il faudrait élaborer et implanter des moyens efficaces de transmission du savoir pour améliorer le transfert des recommandations issues des principes directeurs en milieu clinique.

${ }^{1}$ Centre for Clinical Epidemiology and Evaluation, University of British Columbia, Vancouver, British Columbia; ${ }^{2}$ Institut de cardiologie et de pneumologie de l'Université Laval, Hôpital Laval, Quebec City, Quebec; ${ }^{3}$ Firestone Institute for Respiratory Health, St Joseph's Healthcare,

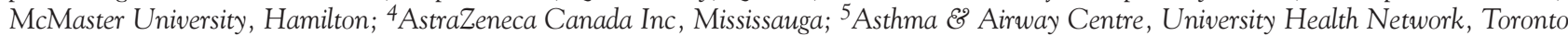
Western Hospital, University of Toronto, Toronto, Ontario

Correspondence: Dr J Mark FitzGerald, Centre for Clinical Epidemiology and Evaluation, Vancouver General Hospital Research Pavilion, 828 10th Avenue West, Vancouver, British Columbia V5Z 1L8. Telephone 604-875-4565, fax 604-875-5179, e-mail markf@interchange.ubc.ca 


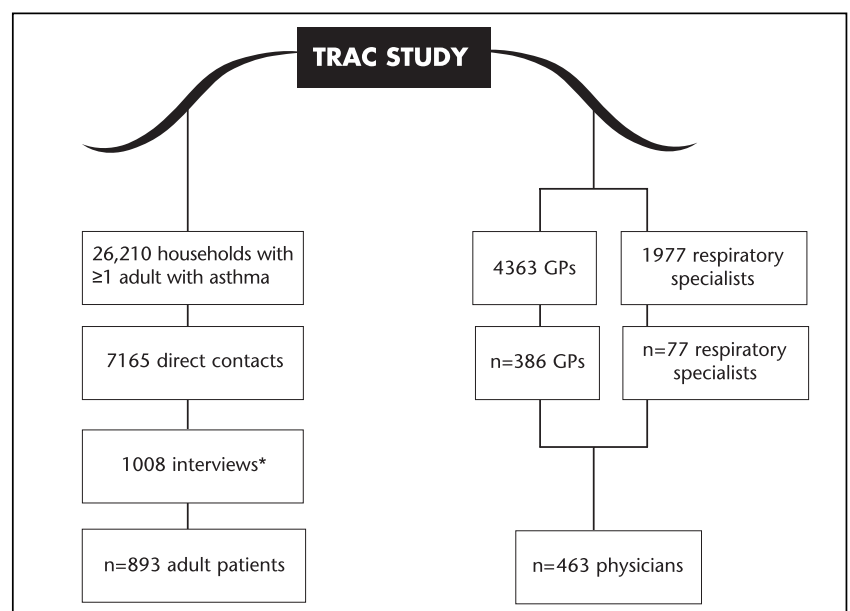

Figure 1) Recruitment and enrollment in The Reality of Asthma Control (TRAC) study. See Table 2 for the derivation of the number of 'direct contacts'. *From this cohort, patients with no physician diagnosis of asthma, a diagnosis within the previous six months or a smoking history of 20 pack-years or more were excluded. GPs Primary care physicians

The Reality of Asthma Control (TRAC) study was undertaken to update and expand on the previous work, and to focus particularly on asthma worsenings and exacerbations, examining how patients and their health care providers actually manage deteriorating asthma. TRAC also evaluated participants' attitudes toward evolving self-management strategies. The study hypothesis was that the degree of asthma control had not changed in recent years despite all efforts to improve care. The present paper reviews the TRAC survey methodology and compares this Canadian asthma experience with the literature, especially with other surveys.

\section{METHODS}

The physician and patient surveys were pretested, the Institutional Review Board Services provided ethics approval, and the surveys were conducted between April and August 2004.

The physician survey used a random sample of Canadian primary care and specialist physicians (respirologists or internists who had reported a subspecialty in respirology) who were currently treating patients with asthma. Physicians were excluded from the sample if they said that more than $90 \%$ of their patients were younger than 18 years of age. The physician survey was initially designed to be carried out by telephone. Due to the low response rate, a mail-out questionnaire, which took approximately $25 \mathrm{~min}$ to complete, was devised. Telephone interviews were conducted with 52 physicians, and the rest mailed their surveys in.

For the patient survey, ICOM Information \& Communications Inc (Toronto, Ontario) furnished a national list of households in which at least one person reported having asthma. Patients eligible for inclusion were 18 to 54 years of age, had been diagnosed with asthma by a physician at least six months before enrollment, did not have chronic obstructive pulmonary disease and had a smoking history of fewer than 20 pack-years. Interviews were allocated according to flexible regional quotas, which were increased in the field to increase the number of completed interviews in regions with smaller populations. At least five telephone calls were made to a household before it was classified as 'no answer'. When a household had more than one qualified person, the subject was chosen according to the most recent birthday. The telephone survey
TABLE 1

Regional quota details of the patient survey

\begin{tabular}{lccccc}
\hline Region & $\begin{array}{c}\text { Initial } \\
\text { quota }\end{array}$ & $\begin{array}{c}\text { First sample } \\
\text { (before } \\
\text { exclusions) }\end{array}$ & $\begin{array}{c}\text { Final } \\
\text { sample } \\
\text { (weighted) }\end{array}$ & $\begin{array}{c}\text { Final } \\
\text { sample } \\
\text { (unweighted) }\end{array}$ & $\begin{array}{c}\text { Margin } \\
\text { of } \\
\text { error* }\end{array}$ \\
\hline Atlantic $^{\dagger}$ & 98 & 109 & 96 & 93 & 10.2 \\
Quebec $^{\text {Ontario }}{ }^{\dagger}$ & 254 & 255 & 218 & 218 & 6.6 \\
Manitoba/ $^{\text {Saskatchewan }}{ }^{\dagger}$ & 412 & 362 & 331 & 334 & 5.4 \\
Alberta & 90 & 100 & 90 & 93 & 10.2 \\
British Columbia & 92 & 92 & 74 & 74 & 11.2 \\
Total & 1010 & $1008^{\ddagger}$ & 893 & $893 \S$ & 3.3 \\
\hline
\end{tabular}

*Expressed as percentage points, plus or minus; 'While the survey was in the field, these quotas were modified; specifically, Ontario's allocation was reduced, and allocations for the Atlantic provinces, Manitoba/Saskatchewan and Alberta were increased to a goal of 100 each; ${ }^{\ddagger}$ Two and $\S$ five patients with incomplete surveys were omitted

took approximately $35 \mathrm{~min}$ to complete. The final patient sample was weighted by sex to reflect the breakdown of asthma in the Canadian population: $58 \%$ women and $42 \%$ men (12).

Patients were classified as having controlled or uncontrolled asthma according to their answers to specific survey questions about the six symptom-based criteria of control outlined in the Canadian Asthma Consensus Guidelines (1). The guidelines specify acceptable control as having daytime symptoms fewer than four days per week, night-time symptoms fewer than one night per week, no limitations on physical activity, mild and infrequent exacerbations, no absences from work or school, and fewer than four dosages per week of short-acting beta-2-agonists (SABAs) (1). Patients who failed two or more of the survey's six parameters of control were classified as having uncontrolled asthma. Asthma worsening was defined as a time during the past year when symptoms increased; asthma exacerbation was defined as an episode that required acute care (unscheduled physician visit, emergency department visit or overnight hospitalization in the past year).

Data were analyzed using SPSS (SPSS Inc, USA) and simple descriptive statistics, and Student's $t$ test was used for comparisons between groups. The $95 \%$ confidence limits were $\pm 3.35 \%$ (patient sample) and $\pm 4.6 \%$ (physician sample).

\section{RESULTS}

Figure 1 shows the number of patients from each group enrolled in the study, and Tables 1 and 2 detail patient recruitment and survey completion results. The mean age of the patients was 39.2 years. Response rates were $7 \%$ for the patient survey and $7.3 \%$ for the physician survey (3.9\% for specialists versus $8.8 \%$ for primary care physicians). Most patients were nonsmokers (58\% had never smoked) and $12 \%$ were current smokers. By highest level of schooling, patients were more educated than the national average (13): $22 \%$ had completed high school (versus $14 \%$ nationally); $37 \%$ had attended community college or trade school (versus 29\%), and 35\% had attended or graduated from university or a professional school (versus 26\%).

Most of the specialists were male $(88 \%)$, in practice for a mean of 21.8 years, and working in either a solo practice or a hospital setting (76\%) in a city (97\%). Most of the family physicians were male $(78 \%)$, in practice for a mean of 21.2 years, and working in either a shared office or solo practice $(85 \%)$ in a city $(77 \%)$ or small town $(20 \%)$. 
TABLE 2

Completion results for the patient survey

\begin{tabular}{lc}
\hline & $\mathbf{n}(\%)^{*}$ \\
\hline Total dialed sample & $26,210(100)$ \\
Household not eligible & $9885(38)$ \\
Nonresidential/not in service & $2484(9)$ \\
Language barrier & $137(1)$ \\
Subtotal & $12,506(48)$ \\
New base $(26,210-12,506)$ & $13,704(100)$ \\
No answer/line busy/ & $6539(48)$ \\
$\quad$ respondent not available & \\
Refusals & $6128(45)$ \\
Mid-interview refusals & $29(<1)$ \\
Excluded interviews & \\
Subtotal & $115(1)$ \\
Net completions $(13,704-12,811)$ & $12,811(93)$ \\
Completion rate $(893 /[13,704-6539])$ & $893(7)$ \\
\hline
\end{tabular}

'Direct contacts' used in Figure 1 is derived from the number in the 'new base' minus the number in the category of no answer/line busy/respondent not available $\left(13,704-6539=7165\right.$ patients). ${ }^{*}$ Percentages may not add up to 100 due to rounding; 'See Table 1 for regional quotas

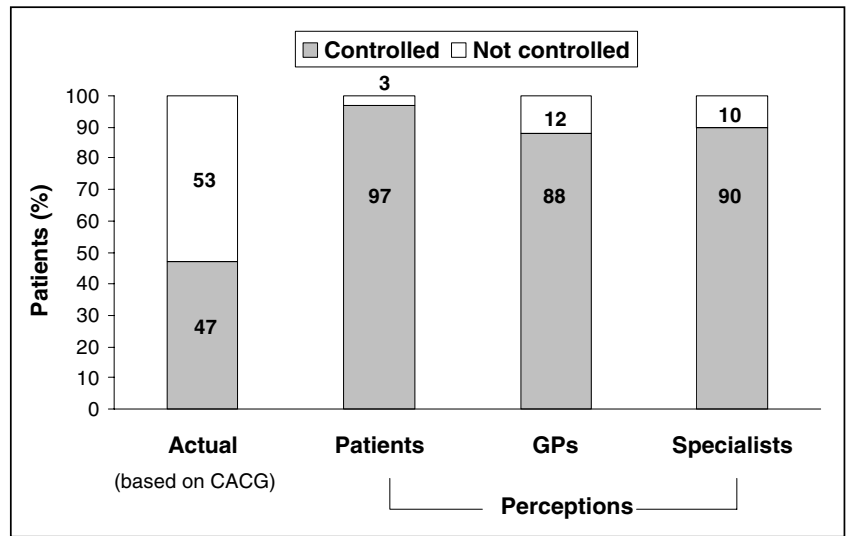

Figure 2) Uncontrolled asthma in Canada. According to the objective criteria of the Canadian Asthma Consensus Guidelines (CACG) (1), $53 \%$ of 893 patients had uncontrolled asthma; however, only 3\% of patients thought that their asthma was uncontrolled. Survey question: "Overall, would you say your asthma is very well controlled, somewhat well controlled, not very well controlled, or not at all controlled?" (the response of $97 \%$ includes those who answered very well [59\%] and somewhat well [38\%] controlled). Specialists $(n=77)$ and primary care physicians (GPs) $(n=386)$ also underestimated the percentage of patients with uncontrolled asthma. Survey question: "Overall, do you feel you are achieving control of your patients' asthma?" (n=463)

Of the 893 asthmatic patients, 53\% ( $n=474)$ had uncontrolled disease. Both physicians and patients grossly underestimated the magnitude of uncontrolled asthma (Figure 2). When asked to define asthma control, physicians most commonly responded in terms of the frequency or amount of medication used (Figure 3). Patients with uncontrolled asthma were most likely to fail the guideline criteria on the parameter of exacerbations: $81 \%$ of patients with uncontrolled disease versus $16 \%$ with controlled disease $(\mathrm{P}<0.01)$. Patients with uncontrolled asthma were also approximately 10 times more likely than those with controlled disease to have had daytime symptoms four or more days per week, night-time symptoms one or more nights per week, and absences from work or school (all $\mathrm{P}<0.01$; Table 3).

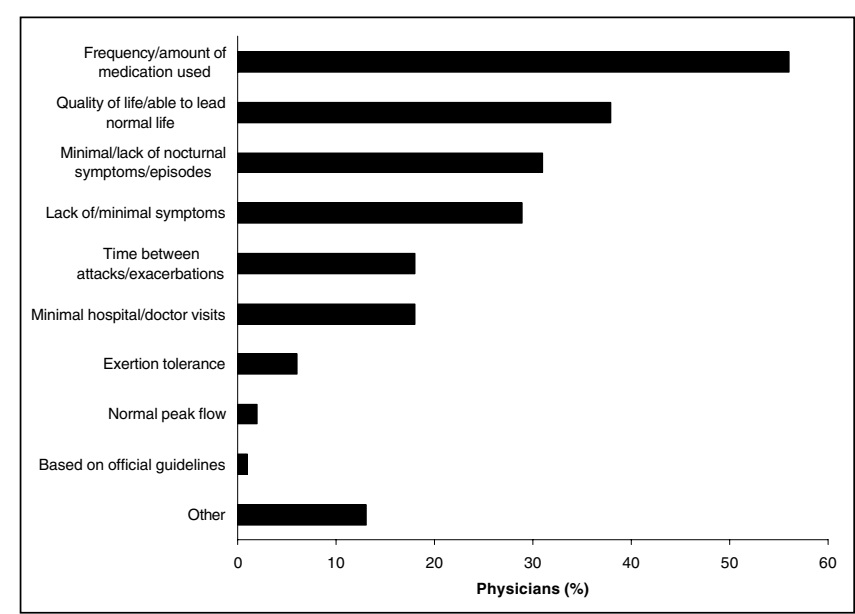

Figure 3) Physicians' definition of asthma control. Survey question: "How do you define control for an asthma patient?" ( $n=463)$

TABLE 3

Patients' scores on six Canadian Asthma Consensus Guidelines (1) parameters of control

\begin{tabular}{|c|c|c|c|}
\hline $\begin{array}{l}\text { Guideline parameter } \\
\text { of control }\end{array}$ & $\begin{array}{c}\text { Total } \\
\text { patient group } \\
(\%)(n=893)\end{array}$ & $\begin{array}{c}\text { Controlled } \\
\text { asthma patients } \\
(\%)(n=418)^{*}\end{array}$ & $\begin{array}{c}\text { Uncontrolled } \\
\text { asthma patients } \\
(\%)(n=474)^{\star}\end{array}$ \\
\hline \multicolumn{4}{|l|}{ Daytime symptoms } \\
\hline$<4$ days per week & 82 & 97 & 69 \\
\hline$\geq 4$ days per week & 18 & 3 & 32 \\
\hline \multicolumn{4}{|l|}{ Night-time symptoms } \\
\hline$<1$ night per week & 71 & 95 & 50 \\
\hline$\geq 1$ night per week & 29 & 5 & 50 \\
\hline \multicolumn{4}{|l|}{ SABA use } \\
\hline$<4$ times per week & 73 & 92 & 57 \\
\hline$\geq 4$ times per week & 27 & 8 & 43 \\
\hline \multicolumn{4}{|l|}{ Physical activity } \\
\hline Did not stop & 64 & 87 & 44 \\
\hline Stopped & 36 & 13 & 56 \\
\hline \multicolumn{4}{|l|}{ Absenteeism } \\
\hline No & 72 & 95 & 51 \\
\hline Yes & 28 & 5 & 49 \\
\hline \multicolumn{4}{|l|}{ Exacerbation } \\
\hline No & 50 & 84 & 19 \\
\hline Yes & 50 & 16 & 81 \\
\hline
\end{tabular}

*The numbers of controlled $(n=418)$ and uncontrolled $(n=474)$ patients omit one of the 893 patients, who could not be classified because of 'don't know' responses or no answer to questions eliciting information about the respondent's asthma control. SABA Short-acting beta-2-agonist

Figure 4 depicts the asthma medication regimens of patients with controlled and uncontrolled asthma. Overall, 29\% of patients were taking only inhaled short-acting bronchodilators for asthma, 40\% were using inhaled corticosteroid (ICS) maintenance therapy with a quick reliever, and $22 \%$ were using a combination of an ICS and a long-acting beta-2-agonist (LABA) in addition to a SABA. Slightly more patients with controlled rather than uncontrolled disease took a bronchodilator alone. Among patients who took an ICS-containing regimen for asthma, most patients, regardless of their selfperceived asthma severity, took a low-dose ICS; the exceptions occurred in some groups with extremely small patient numbers (Table 4). Two-thirds (66\%) of patients with uncontrolled asthma were taking an ICS. 


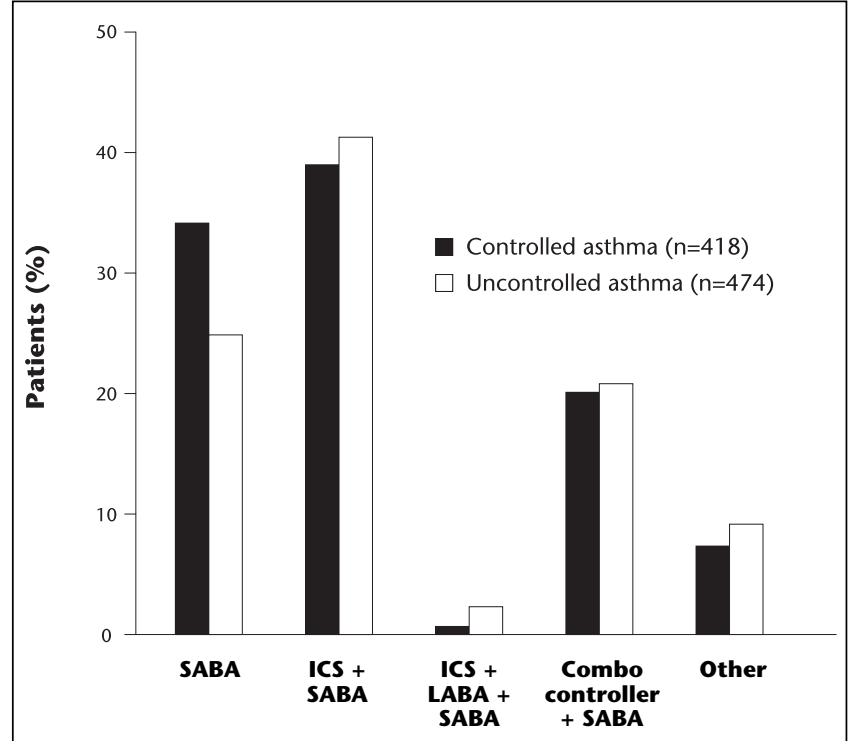

Figure 4) Percentages of patients taking classes of prescription medications for asthma. Combo Combination of an inhaled corticosteroid (ICS) and a long-acting beta-2-agonist (LABA) in a single inhaler. SABA Short-acting beta-2-agonist

Although $90 \%$ of physicians reported awareness of the Canadian asthma guidelines, only $6 \%$ of both specialists and primary care physicians always used the guidelines, and $33 \%$ of both groups based their asthma recommendations on the guidelines 'most of the time'. The majority of physicians (59\%) regularly used or recommended an adjustable dosing regimen, with a small but significant difference between primary care physicians and specialists. Compared with $45 \%$ of specialists, $62 \%$ of primary care physicians favoured an adjustable dosing regimen $(\mathrm{P}<0.001)$. Eight of 10 physicians thought it was best to control asthma with the least amount of medication possible, and the majority of patients $(88 \%)$ wanted to use lower medication doses. Compared with patients with controlled asthma, those with uncontrolled disease were more likely to have changed their daily maintenance or controller medication on their own to deal with their asthma symptoms without having consulted a health professional (31\% versus $18 \% ; \mathrm{P}<0.01)$.

Although $80 \%$ of physicians said that they provided verbal action plans and $22 \%$ provided written plans, $44 \%$ of patients reported having neither. Of those physicians who thought that action plans were important ( $\mathrm{n}=442$ ), 56\% thought that the plan should be written. By far the most common reason for not giving a patient a written asthma action plan was a lack of time (59\%). Patients with uncontrolled disease were more likely than controlled-disease patients to have an action plan (61\% had written, spoken, or both, versus 50\%; $\mathrm{P}<0.01$; Figure 5). Among those with an asthma action plan $(n=496), 50 \%$ did not use it regularly (45\% with controlled disease and $54 \%$ with uncontrolled disease), even though virtually all patients said that it was easy to follow.

Specialists were more likely than primary care physicians to send patients to a pulmonary function laboratory for spirometry ( $90 \%$ versus $79 \%$, respectively; $\mathrm{P}<0.01$ ) and to use spirometry to monitor patients' status ( $75 \%$ versus $46 \%$, respectively; $\mathrm{P}<0.01$ ). However, only $10 \%$ of surveyed patients reported having gone to a laboratory for spirometry; in addition, $25 \%$ thought that they had undergone spirometry in a doctor's office. The survey asked, "In the past year, has your doctor measured your lung function in his/her office by having you blow forcefully into a measuring machine called a spirometer, or has he/she asked that you go to a laboratory for such measurements?"

Physicians almost unanimously agreed (98\% strongly or somewhat agreed) that patients needed more asthma education, and patients concurred $(93 \%$ with uncontrolled disease versus $95 \%$ with controlled disease). Surveyed patients provided several examples of education needs. Although $67 \%$ of patients knew of the term 'reliever', only 59\% of their reliever examples belonged to the class (Figure 6A), and 24\% stated that relievers should be used regularly. Similarly, even though $74 \%$ of patients reported familiarity with the term 'controller' (the study classified LABAs and combination medications as controllers), just $63 \%$ of their controller examples belonged to

\section{TABLE 4}

\section{Inhaled corticosteroid (ICS) dose in three ICS-containing regimens, classified by patients' perception of their asthma} severity and an objective classification of control

\begin{tabular}{|c|c|c|c|c|c|c|}
\hline $\begin{array}{l}\text { ICS + SABA } \\
(n=317)^{*}\end{array}$ & $\begin{array}{l}\text { Mild, controlled } \\
\quad(\%)(n=90)\end{array}$ & $\begin{array}{l}\text { Mild, uncontrolled } \\
(\%)(n=82)\end{array}$ & $\begin{array}{c}\text { Moderate, controlled } \\
(\%)(n=39)\end{array}$ & $\begin{array}{c}\text { Moderate, uncontrolled } \\
(\%)(n=86)\end{array}$ & $\begin{array}{l}\text { Severe, controlled } \\
(\%)(n=4)\end{array}$ & $\begin{array}{l}\text { Severe, uncontrolled } \\
(\%)(n=14)\end{array}$ \\
\hline Moderate dose & 18 & 27 & 19 & 30 & 59 & 33 \\
\hline $\begin{array}{l}\text { ICS + LABA + SABA } \\
(\mathrm{n}=17)^{\dagger}\end{array}$ & $(n=2)$ & $(n=6)$ & $(n=1)$ & $(n=2)$ & $(n=0)$ & $(n=5)$ \\
\hline Low dose & 50 & 14 & 100 & 50 & - & 85 \\
\hline High dose & 50 & 58 & - & 50 & - & 15 \\
\hline $\begin{array}{l}\text { Combo controller + } \\
\text { SABA }(n=161)^{\ddagger}\end{array}$ & $(n=38)$ & $(n=27)$ & $(n=24)$ & $(n=50)$ & $(n=6)$ & $(n=14)$ \\
\hline Low dose & 91 & 71 & 87 & 68 & 62 & 72 \\
\hline Moderate dose & 6 & 23 & 13 & 22 & - & 17 \\
\hline High dose & 2 & 6 & - & 10 & 38 & 11 \\
\hline
\end{tabular}

The Canadian Asthma Consensus Guidelines (3) provide the ICS dose classification (eg, budesonide Turbuhaler, AstraZeneca Canada Inc): low dose, 400 Mg/day or less; moderate dose, $401 \mu \mathrm{g} /$ day to $800 \mu \mathrm{g} / \mathrm{day}$; and high dose, greater than $800 \mu \mathrm{g} / \mathrm{day}$. ${ }^{*} T w o,{ }^{\dagger}$ one and ${ }_{\text {two }}$ patients were omitted because they could not be classified due to 'don't know' responses or no answer to questions eliciting information about the respondents' perception of asthma severity or objective asthma control. Combo Combination of an ICS and a long-acting beta-2-agonist (LABA) in a single inhaler; SABA Short-acting beta-2-agonist 


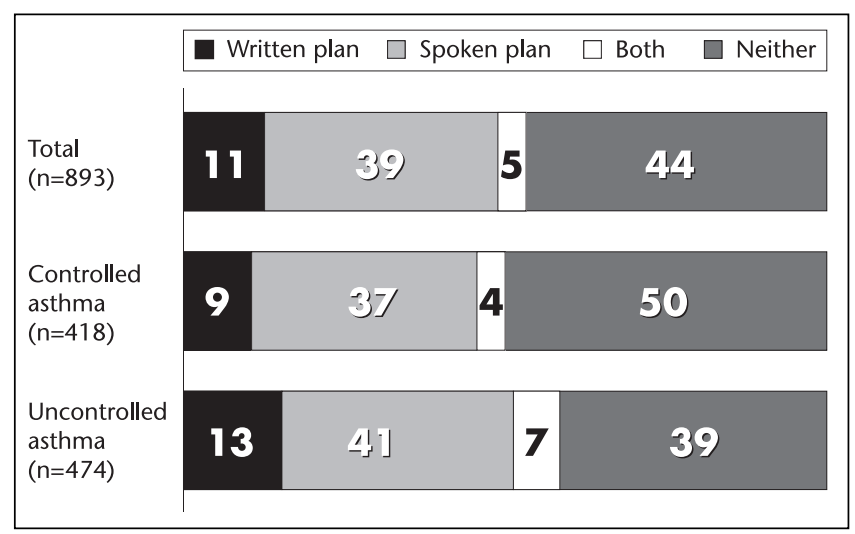

Figure 5) Percentages of patients possessing asthma treatment plans. Survey question: "Do you have an asthma treatment plan that is either written or spoken instructions of what to do if your asthma gets worse?"

the class (Figure 6B), and 26\% of patients stated that controllers should be used as needed. The majority of patients were very or somewhat concerned about medication side effects ( $72 \%$ of patients with controlled asthma versus $81 \%$ of those with uncontrolled asthma). Almost three-quarters expressed concerns about taking an ICS. This concern was reflected in the desire of $81 \%$ of patients to use less ICS over the long term. According to physicians, education and comprehension issues were the main factors $(41 \%)$ associated with poor adherence. The survey asked, "In your opinion, what factors are most likely to lead to patient noncompliance?" Of the 463 physicians, $21 \%$ cited education issues, and $20 \%$ cited understanding/ comprehension of asthma and its treatment.

\section{DISCUSSION}

The asthma of Canadian adults remains poorly controlled, despite the availability of excellent treatments and a framework for their use, namely, the Canadian Clinical Practice Guidelines (1). Although the parameters described here show poor ongoing asthma control in the community, it should be noted that there has been a significant decline in hospitalizations for acute asthma in Canada over the past 20 years (14). A 1999 Canadian asthma study revealed that $57 \%$ of patients had poorly controlled disease (4) versus $53 \%$ in TRAC. Both studies used the same six asthma control criteria, which were based on the published guidelines. TRAC enrolled adult patients, whereas an earlier Canadian study (4) and a companion American study (8) included responses from parents of children who had asthma. A global survey (North America, Europe and Asia) (15), and studies in the United States (8), Europe (9) and Asia-Pacific (10) have all reported that asthma control fell far below goals (eg, an estimated six million Americans suffer from moderate or severe persistent symptoms) (8) and that patients consistently underestimated their degree of asthma control.

Both physicians and patients in TRAC exhibited knowledge deficits, compounded by a communication gap. This survey clearly shows that both groups had low expectations of symptom control, and patients remained confused about the differences between controller and reliever medications and when to use each type of drug. Because some patients stop treatment when their symptoms improve, they cannot recognize the importance of maintenance therapy to treat the underlying inflammation.

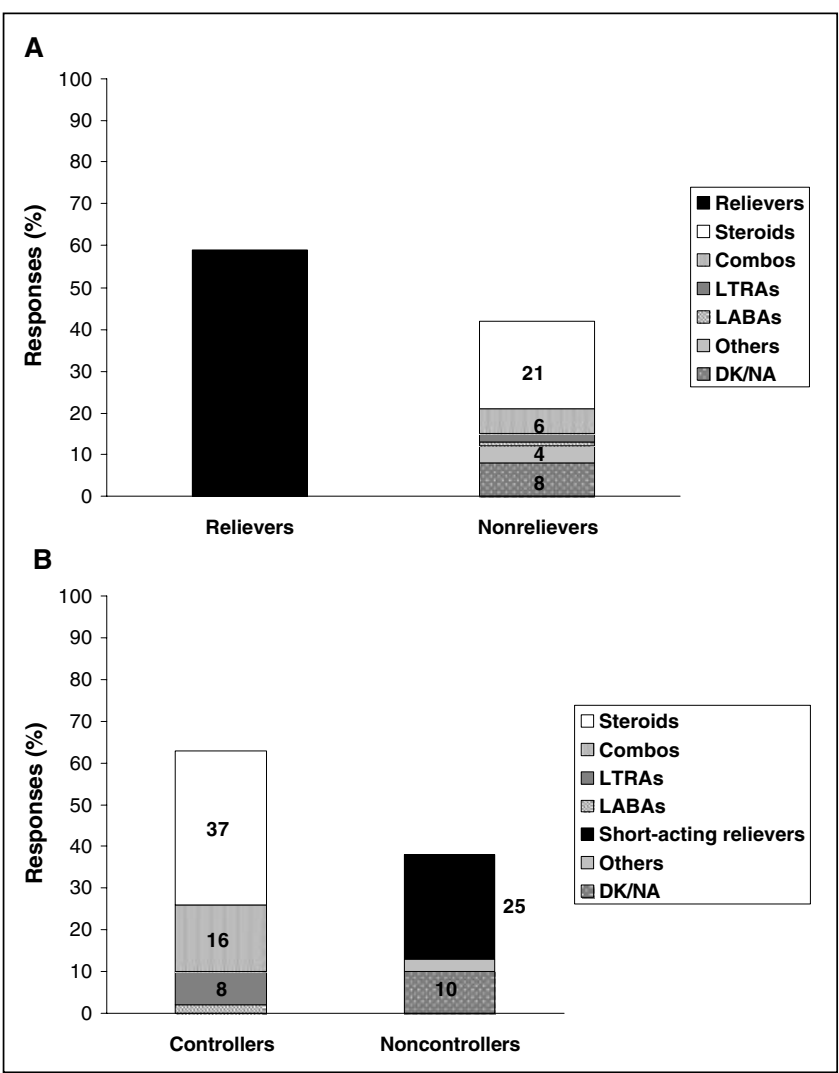

Figure 6) Knowledge of reliever and controller medications in the subsets of patients who had heard of each type of medication ( $n=594$ for relievers; $n=661$ for controllers). Survey questions: "Have you ever heard of 'reliever'/"controller' medications for asthma?" and "Can you name one or more reliever/controller medications?" (note that respondents were permitted to give more than one answer). The figure categorizes the patients' examples of relievers (A) and controllers (B). Response percentages (of total drug mentions) may not add up to 100 because of rounding. Combos Combination of an inhaled corticosteroid and a long-acting beta-2-agonist (LABA) in a single inhaler; DK Don't know; LTRAs Leukotriene-receptor antagonists; NA No answer

Despite a recent report by Boushey et al (16), which suggested that intermittent ICS may have a role to play in the management of very mild asthma, it is important to realize that the majority of patients with mild-to-moderate persistent asthma require regular anti-inflammatory therapy. This need is well supported by large prospective studies such as the Inhaled Steroid Treatment as Regular Therapy in Early Asthma (START) trial (17), which showed that even in patients with apparently mild disease, severe asthma exacerbations can occur, and that an ICS has a protective role. TRAC found that almost three-quarters of patients were concerned about the side effects of ICS and eight of 10 patients hoped to decrease their ICS usage. These results indicate that some health care professionals are failing to communicate the benefits of an ICS or to put the risks in context. An earlier Canadian national telephone survey revealed the same worries: more than one-half of 603 adults with asthma were very or somewhat concerned about using an ICS regularly, and two-thirds had not discussed their concerns with a health care professional (18). After reassurance, $75 \%$ of patients in this study were comfortable with using an ICS (18).

Many studies have attempted to close the gap between patients' knowledge about asthma treatment and actual practice. 
Kolbe and colleagues $(19,20)$ used scenarios describing hypothetical asthma exacerbations to assess practical knowledge of asthma self-management. Patients' responses to the scenarios paralleled errors that patients made in real clinical situations, with psychological and socioeconomic factors influencing behaviour (20). Diamond and Chapman (21) demonstrated that a brief assessment and educational intervention in the community pharmacy produced significant 30-day improvements in patient-reported symptoms and self-management. To address educational deficits, physicians may need to understand and implement improved methods of knowledge transfer to patients. Perhaps guidelines should include a section on education techniques for knowledge transfer, and tools for adult learning and patient education. In addition, physicians may need to perform more frequent assessments of how well patients understand educational messages and follow-up with remedial action if indicated. The physicians interviewed for the TRAC survey identified inadequate education and poor comprehension as important factors in noncompliance with controller therapy.

The major goal of physicians' continuing medical education on asthma is to improve medical care through more effective translation of guideline recommendations into practice. Traditional (didactic) continuing education has failed to lead to guideline implementation, and approaches tailored to local factors may be necessary (22). In TRAC, although physicians' awareness of the Canadian asthma guidelines was high, a significant number of physicians ignored them. Guidelines are especially relevant in the assessment of control, when a global question of "How is your asthma?" could elicit an underestimation of the degree of control. In contrast, symptom-specific questions such as "Are you waking at night?" and "How often are you using your rescue medication?" could improve the assessment. Clearly, without an accurate definition of control (TRAC revealed knowledge deficits in this area) and without an accurate definition of the level of control obtained from symptom-specific patient assessment, physicians cannot initiate appropriate therapeutic strategies, particularly if they omit objective tests. The gap between the high spirometry rate according to physicians and the low rate according to patients in TRAC suggests a discrepancy between what physicians report and what really happens.

In addition to falling short in assessing according to guidelines, physicians often did not follow the guidelines for treatment. LABAs were absent from the top prescription drugs patients mentioned, although the guidelines recommend them as an alternative to increased doses of an ICS and as add-on therapy to moderate or higher doses of an ICS to achieve control of persistent asthma symptoms (level I evidence) (1). Many patients in the present study were taking an ICS and a SABA without having had their controller dose adjusted upwards to achieve optimum control. The results of TRAC demonstrate that physicians treated patients with controlled and uncontrolled asthma similarly. This finding suggests that physicians prescribe in a rote fashion, without assessing control and taking it into account when making prescription decisions. Physicians often failed to individualize treatment, especially by instructing their patients about how to adjust their medications in accordance with their symptoms.

Education has fallen short in the value of action plans, the ease of implementing them in practice, and the availability of resources such as asthma education centres. The use of written action plans was found to be only $2 \%$ in a large chart review completed in primary care in Alberta (23). In this study, significantly more patients with uncontrolled asthma had action plans than patients with controlled disease. Perhaps patients with uncontrolled disease received slightly more education and preparation for asthma exacerbations than their wellcontrolled counterparts. However, their uncontrolled status seemingly contradicts the observations from other studies, including those from a Cochrane meta-analysis (24) that showed that written action plans improve outcomes. However, it should be noted that almost one-half of TRAC patients with uncontrolled asthma and an action plan ignored it. In addition, a written action plan is unlikely to be effective unless it is accompanied not only by verbal instructions but also by regular evaluation of the plan's implementation. The greatest barrier for TRAC physicians to the use of written asthma action plans was the lack of time. To overcome this barrier, asthma educators can provide invaluable support to physicians. A Canadian study increased the number of referrals to asthma education centres 10 -fold by implementing a model for automatic referral that targeted patients with acute asthma who presented to emergency departments (25).

The study had some limitations. The low response rate may indicate that patients and physicians who were satisfied with the prevailing situation did not respond. The results do not identify specific education issues that lead to noncompliance, and no data are available on the types or quality of asthma education patients had received (to discern the potential effects of education on patients with controlled versus uncontrolled disease). Because the patient cohort was more educated than the national average, the patient data on confusion about drugs and the need for education likely understate the magnitude of the problems. TRAC's definition of control, with two failed control parameters, is stricter than the definition of the Canadian guidelines, which counts the failure of any single parameter as inadequate control. With the educated patient cohort and the stricter control definition, actual results may again be worse than the present study depicts. Patients may have had trouble remembering an asthma worsening that happened months ago (several survey questions explored specific details of asthma worsenings). To improve the validity of self-reported events that happened up to a year before the study, the study asked patients only about the last worsening. Data on patients who changed medications without consulting a health care professional include patients who changed their medications based on prior instructions. Finally, analyses that group the primary care physicians and specialists in one category bring together somewhat diverse groups and over-represent primary care physicians; the data analysis divided the two groups as much as possible.

\section{CONCLUSIONS}

TRAC confirms that asthma control in Canada remains poor, five years after the last large Canadian asthma survey (4). Superior asthma control is based on efficacy of drugs, taken as prescribed. Even being prescribed the 'right' medication does not guarantee its effectiveness, because of patient and physician factors. The patient may not use the medication properly or may have reached a therapeutic plateau and could obtain better control with combination therapy. Other criteria for effectiveness include a proper diagnosis, environmental control, control of postnasal drip and adherence. 
Addressing all of these factors requires a therapeutic alliance between patient and doctor, respect for patients' health beliefs, and clear communication that motivates patients and reinforces progress (26). Future efforts should focus on the best ways to use the well-established, evidence-based framework for the management of asthma to develop and implement multifaceted intervention strategies for both clinicians and patients with asthma.

FUNDING: The present study was funded by AstraZeneca Canada Inc.

CONFLICT OF INTEREST: Sabrina Zimmerman is a Product Manager at AstraZeneca Canada; all other authors have received funds from a number of pharmaceutical companies including AstraZeneca for activities related to advisory boards, educational programs and research.

\section{REFERENCES}

1. Boulet LP, Becker A, Berube D, Beveridge R, Ernst P; Canadian Asthma Consensus Group. Canadian Asthma Consensus Report, 1999. CMAJ 1999;161(Suppl 11):S1-S61.

2. Boulet L-P, Bai TR, Becker A, et al. What is new since the last (1999) Canadian Asthma Consensus Guidelines? Can Respir J 2001;8(Suppl A):3A-27A.

3. Lemiere C, Bai T, Balter M, et al. Adult Asthma Consensus Guidelines Update 2003. Can Respir J 2003;11(Suppl A):9A-18A.

4. Chapman KR, Ernst P, Grenville A, Dewland P, Zimmerman S. Control of asthma in Canada: Failure to achieve guideline targets. Can Respir J 2001;8(Suppl A):35A-40A.

5. Juniper EF, Svensson K, Mork AC, Stahl E. Measuring health-related quality of life in adults during an acute asthma exacerbation. Chest 2004;125:93-7.

6. Spitzer WO, Suissa S, Ernst P, et al. The use of beta-agonists and the risk of death and near death from asthma. N Engl J Med 1992;326:501-6.

7. McFadden ER Jr, Warren EL. Observations on asthma mortality. Ann Intern Med 1997;127:142-7.

8. GlaxoSmithKline. Asthma in America: A landmark survey. $<$ http://www.asthmainamerica.com > (Version current at June 27, 2006).

9. Rabe KF, Vermeire PA, Soriano JB, Maier WC. Clinical management of asthma in 1999: The Asthma Insights and Reality in Europe (AIRE) study. Eur Respir J 2000;16:802-7.

10. Lai CK, De Guia TS, Kim YY, et al; Asthma Insights and Reality in Asia-Pacific Steering Committee. Asthma control in the AsiaPacific region: The Asthma Insights and Reality in Asia-Pacific Study. J Allergy Clin Immunol 2003;111:263-8.
11. Joyce DP, McIvor RA. Use of inhaled medications and urgent care services. Study of Canadian asthma patients. Can Fam Physician 1999;45:1707-13.

12. Statistics Canada. Canadian Community Health Survey, 2003. Ottawa: Statistics Canada, 2004: Survey number 3226. <http://www.statcan.ca/cgi-bin/imdb/p2SV.pl?Function= getSurvey\&SurvId=3226\&SurvVer=0\&InstaId=15282\&InstaVer=2 $\& S D D S=3226 \&$ lang $=$ en $\& \mathrm{db}=\mathrm{IMDB} \& \mathrm{dbg}=\mathrm{f} \& \mathrm{adm}=8 \& \mathrm{dis}=2>$ (Version current at June 27, 2006).

13. Statistics Canada. Population 15 years and over by highest level of schooling, by provinces and territory (2001 Census). <http://www40.statcan.ca/101/cst01/educ43a.htm> (Version current at June 26, 2006).

14. Editorial Board. Asthma. In: Respiratory Disease in Canada. Ottawa: Health Canada, 2001:33-44.

15. Rabe KF, Adachi M, Lai CK, et al. Worldwide severity and control of asthma in children and adults: The global asthma insights and reality surveys. J Allergy Clin Immunol 2004;114:40-7.

16. Boushey HA, Sorkness CA, King TS, et al; National Heart, Lung, and Blood Institute's Asthma Clinical Research Network. Daily versus as-needed corticosteroids for mild persistent asthma. N Engl J Med 2005;352:1519-28.

17. Sheffer AL, Silverman M, Woolcock AJ, Diaz PV, Lindberg B, Lindmark B. Long-term safety of once-daily budesonide in patients with early-onset mild persistent asthma: Results of the Inhaled Steroid Treatment as Regular Therapy in Early Asthma (START) study. Ann Allergy Asthma Immunol 2005;94:48-54.

18. Boulet LP. Perception of the role and potential side effects of inhaled corticosteroids among asthmatic patients. Chest 1998;113:587-92.

19. Kolbe J, Vamos M, James F, Elkind G, Garrett J. Assessment of practical knowledge of self-management of acute asthma. Chest 1996;109:86-90.

20. Kolbe J, Vamos M, Fergusson W, Elkind G, Garrett J. Differential influences on asthma self-management knowledge and self-management behavior in acute severe asthma. Chest 1996;110:1463-8.

21. Diamond SA, Chapman KR. The impact of a nationally coordinated pharmacy-based asthma education intervention. Can Respir J 2001;8:261-5.

22. FitzGerald JM. Development and implementation of asthma guidelines. Can Respir J 1998;5(Suppl A):85A-8A.

23. Tsuyuki RT, Sin DD, Sharpe HM, Nilsson C, Man SF; Alberta Strategy to Help Manage Asthma (ASTHMA) Investigators. Management of asthma among community-based primary care physicians. J Asthma 2005;42:163-7.

24. Gibson PG, Powell H, Coughlan J, et al. Self-management education and regular practitioner review for adults with asthma. Cochrane Database Syst Rev 2003;1:CD001117.

25. Robichaud P, Laberge A, Allen MF, et al. Evaluation of a program aimed at increasing referrals for asthma education of patients consulting at the emergency department for acute asthma. Chest 2004;126:1495-501.

26. Chapman KR, Walker L, Cluley S, Fabbri L. Improving patient compliance with asthma therapy. Respir Med 2000;94:2-9. 


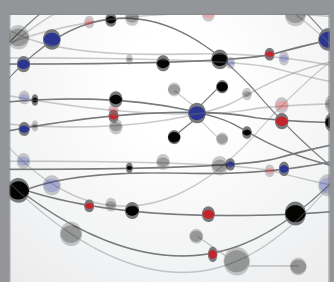

The Scientific World Journal
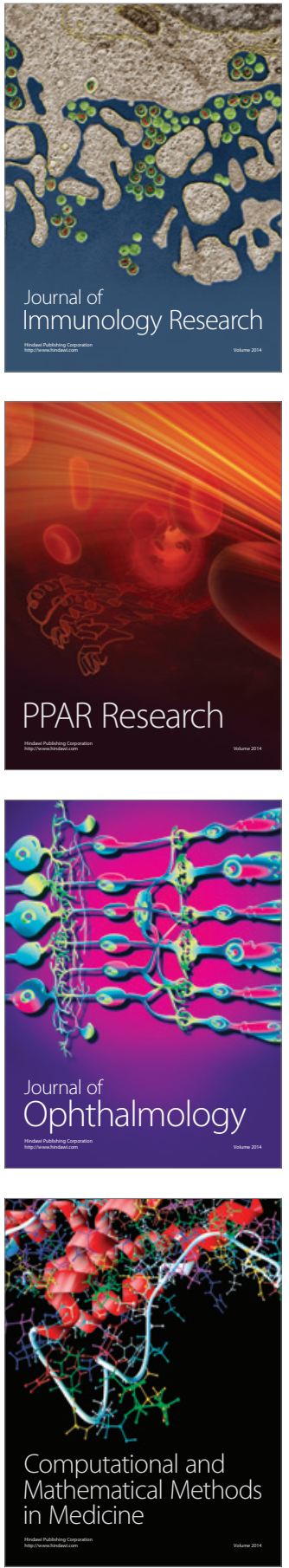

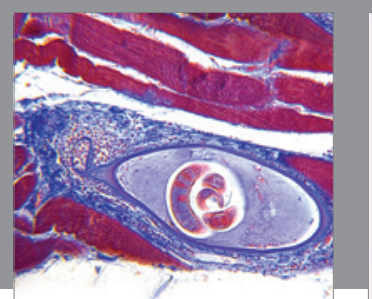

Gastroenterology Research and Practice

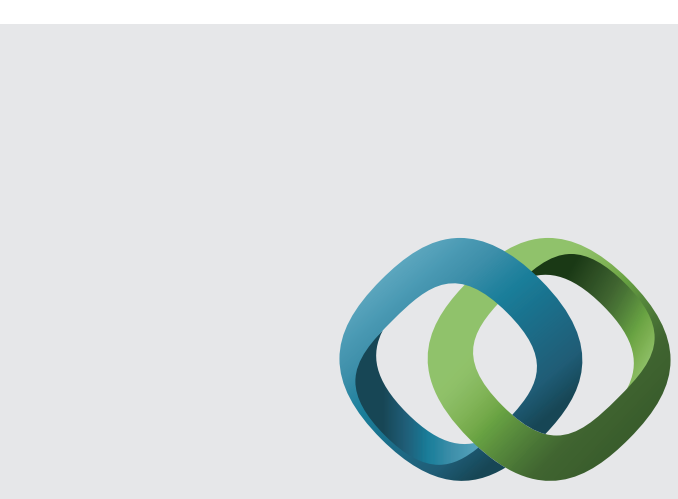

\section{Hindawi}

Submit your manuscripts at

http://www.hindawi.com
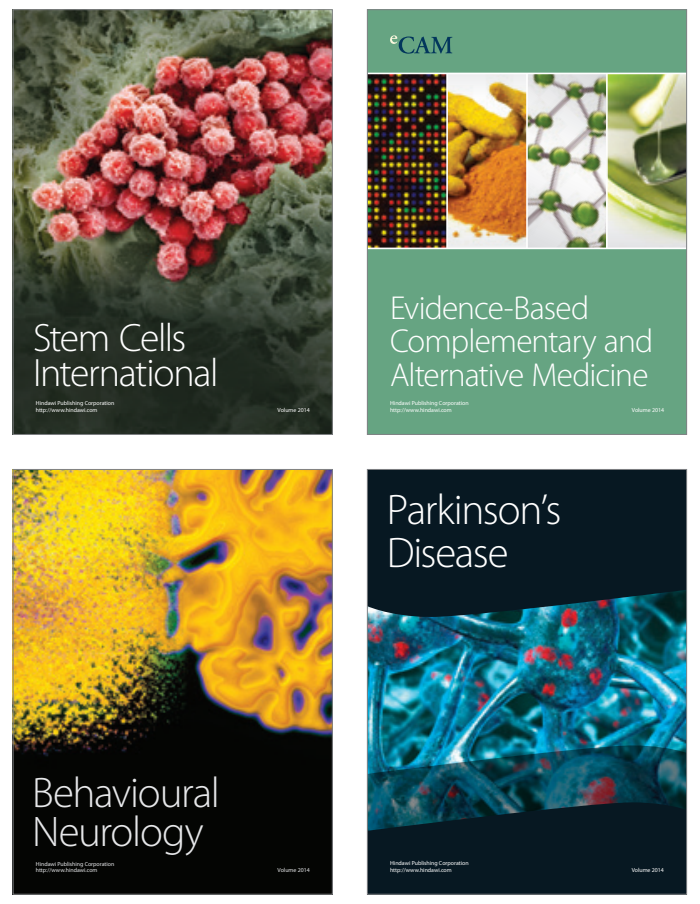
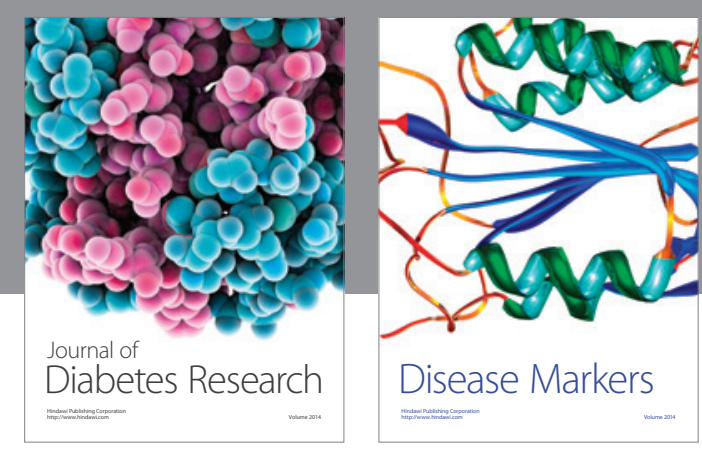

Disease Markers
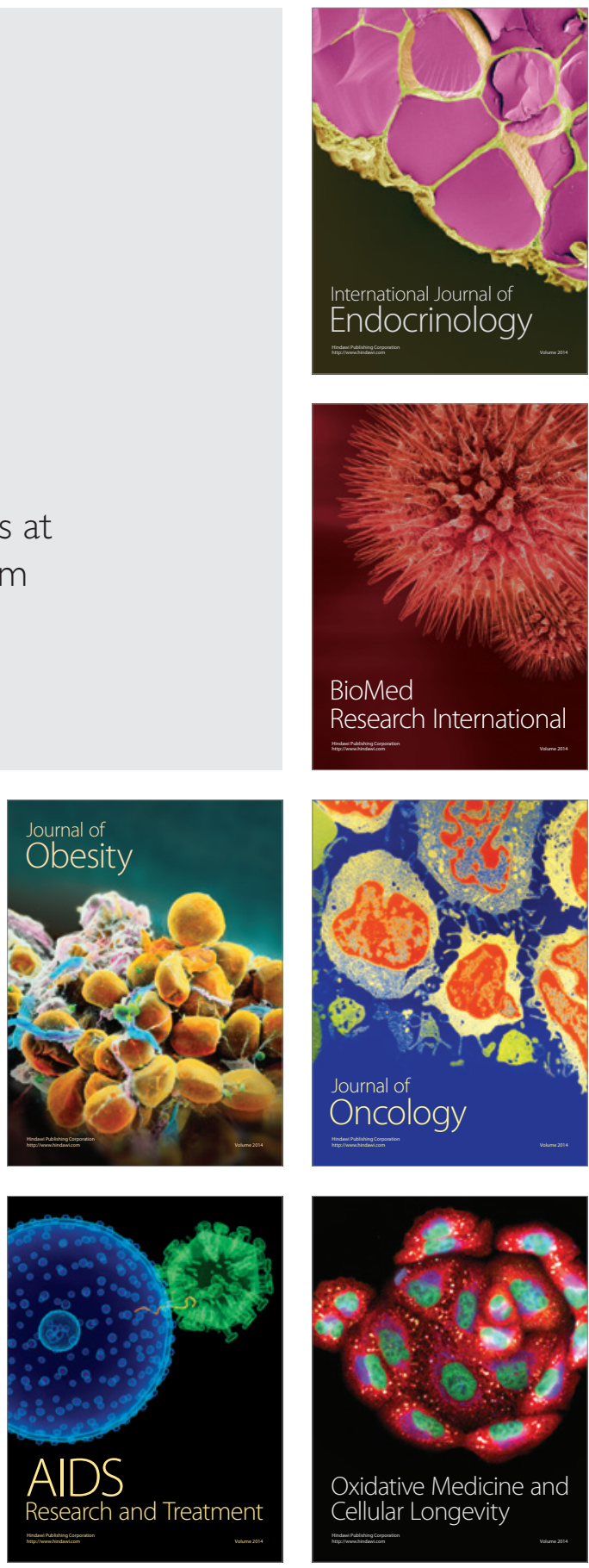